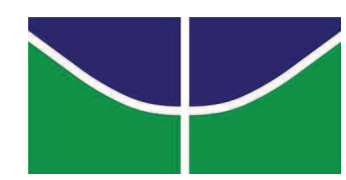

Universidade de Brasília (UnB)

Faculdade de Economia, Administração, Contabilidade e Ciência da Informação e Documentação (FACE)

Programa de Pós-Graduação em Administração (PPGA)

REJANE MARIA MOREIRA DOS SANTOS

\title{
ANÁLISE DE COMPORTAMENTOS DE CIVISMO ORGANIZACIONAL EM UM HOSPITAL UNIVERSITÁRIO
}




\section{ANÁLISE DE COMPORTAMENTOS DE CIVISMO ORGANIZACIONAL EM UM HOSPITAL UNIVERSITÁRIO}

Monografia apresentada à Faculdade de Economia, Administração, Contabilidade e Ciência da Informação e Documentação (FACE), da Universidade de Brasília, como requisito parcial à obtenção do grau de Especialista em Gestão Universitária.

Orientadora: Prof ${ }^{a}$ Dra. Maria de Fátima Bruno de Faria

$$
\text { Brasília - DF }
$$




\section{ANÁLISE DE COMPORTAMENTOS DE CIVISMO ORGANIZACIONAL EM UM HOSPITAL UNIVERSITÁRIO}

Monografia apresentada à Faculdade de Economia, Administração, Contabilidade e Ciência da Informação e Documentação (FACE), da Universidade de Brasília, como requisito parcial à obtenção do grau de Especialista em Gestão Universitária.

Data de aprovação

Profa $^{a}$ Dra. Maria de Fátima Bruno de Faria Orientadora

Profa Dra. Catarina Cecília Odelius

Membro da Banca Examinadora 
A todos que acreditam no meu sucesso, em especial aos meus pais. 


\section{AGRADECIMENTOS}

Agradeço a Deus, que me concede a cada dia desfrutar melhor a vida, de onde eu busco sabedoria e força para enfrentar os desafios, iluminando o meu caminho.

À Professora Fátima Bruno, pela cuidadosa orientação e pela paciência e dedicação ao acompanhar o andamento do trabalho.

A todos os professores do curso, por compartilhar suas experiências profissionais e também pessoais contribuindo para o nosso enriquecimento.

Aos funcionários do Hospital Universitário de Brasília que contribuíram para a pesquisa em especial à Dra. Elza Noronha e Dr. César Augusto pela atenção dispensada, que acreditam e investem no meu crescimento profissional.

À toda equipe da FACE e do PPGA.

E, com muito carinho, agradeço imensamente a todos os colegas de turma com quem partilhei momentos únicos que serão guardados na memória e que com certeza os levarei na lembrança assim como os verdadeiros amigos que cativei. 


\section{RESUMO}

O estudo do comportamento de civismo organizacional tem crescido por ser reconhecida sua importância para sobrevivência e alcance da efetividade organizacional. Este comportamento retrata atos espontâneos dos trabalhadores no ambiente de trabalho, que contribuem para a concretização dos objetivos organizacionais. O presente estudo teve como objetivo realizar uma análise de comportamentos de civismo organizacional em um hospital universitário. Foi aplicada a Escala de Comportamento de Civismo Organizacional, construída e validada por Porto e Tamayo (2003), composta por 41 itens a serem respondidos em uma escala Likert, variando de 1 a 5 . O método de investigação utilizado foi o quantitativo através de levantamento de dados (survey). Foram selecionados 68 colaboradores da Instituição para responder o questionário.O critério para escolha dessa amostra foi que os respondentes tivessem, no mínimo, um ano de vínculo com a Instituição. Os resultados evidenciaram comportamentos de civismo na organização, mesmo se tratando de uma Instituição que integra o sistema de saúde pública que sofre dificuldades, os colaboradores apresentam atos espontâneos que favorecem o sistema. Pode-se observar que as maiores médias apresentadas foram em relação ao fator proteção ao sistema e, em seguida aparece o fator cooperação com os colegas, para estes fatores as respostas situam-se entre frequentemente e sempre, os outros fatores também apresentam médias consideráveis entre às vezes e sempre. Além disso, foram calculadas Correlação de Pearson entre os referidos fatores e as seguintes variáveis demográficas: gênero, faixa etária, nível de escolaridade, tempo de trabalho, tipo de vínculo e tipo de cargo. Para caracterizar a amostra foram utilizados gráficos e tabelas com freqüências e percentuais. Verificouse também que o estudo pode ser ampliado com análise de outras áreas do referido hospital, a fim de estimular tais comportamentos.

Palavras-chave: Civismo Organizacional, Comprometimento Organizacional, Cidadania Organizacional. 


\section{LISTA DE GRÁFICOS}

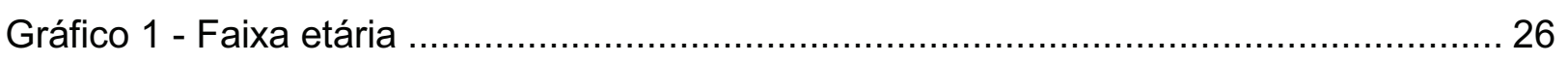

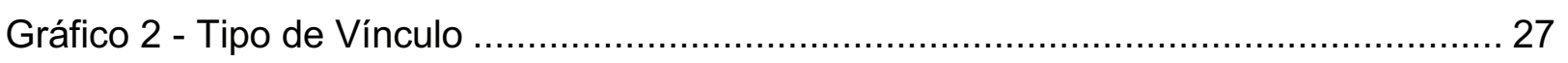

\section{LISTA DE TABELAS}

Tabela 1 - Fatores, índices de confiabilidade e itens da ECO .............................23

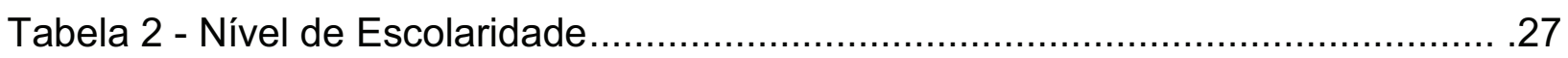

Tabela 3 - Médias e desvios padrões dos fatores de civismo organizacional .............29

Tabela 4 - Correlações significativas com os fatores e as variáveis independentes.....30

Tabela 5 - Estatística descritiva dos itens que compõem o Fator 1 .......................... 31

Tabela 6 - Estatística descritiva dos itens que compõem o Fator $2 \ldots \ldots \ldots \ldots \ldots \ldots \ldots \ldots \ldots . . . \ldots \ldots \ldots$

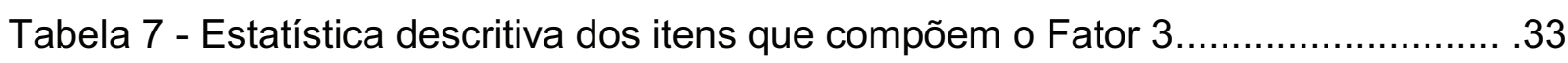

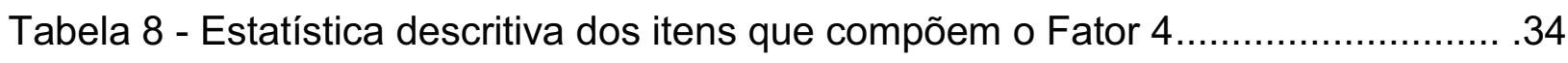

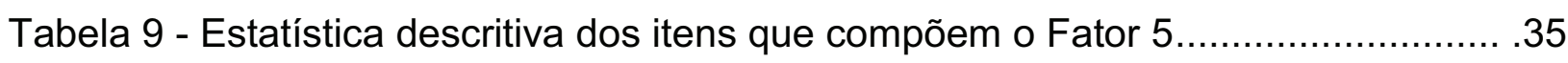




\section{SUMÁRIO}

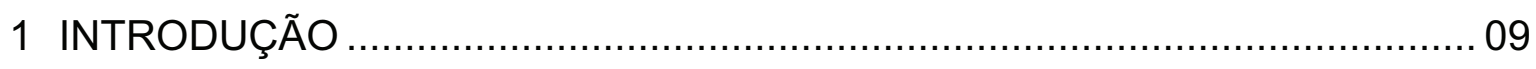

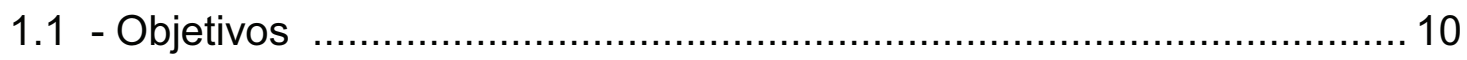

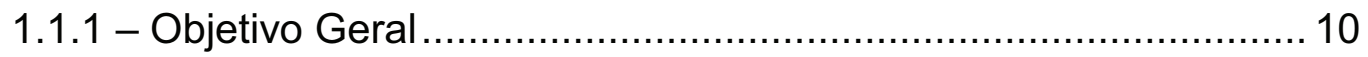

1.1.2 - Objetivos Específicos …………………......................... 10

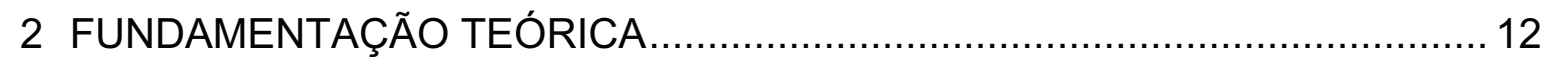

2.1 - Civismo Organizacional e construtos Similares .................................. 12

2.2 - Comportamentos pró-sociais e extrapapel ........................................ 13

2.3 - Cidadania Organizacional e comportamentos de espontaneidade ...... 14

2.4 - Comprometimento Organizacional .................................................. 17

2.5 - Cultura Organizacional ................................................................ 18

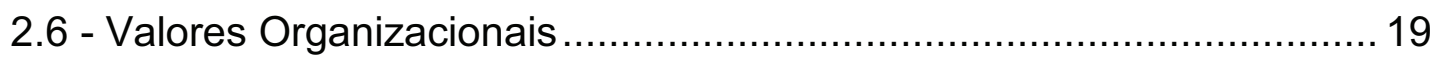

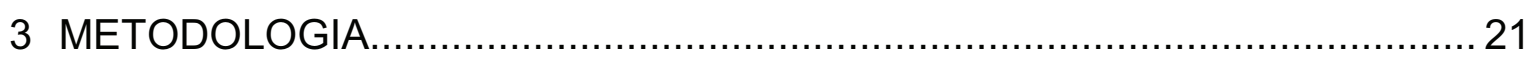

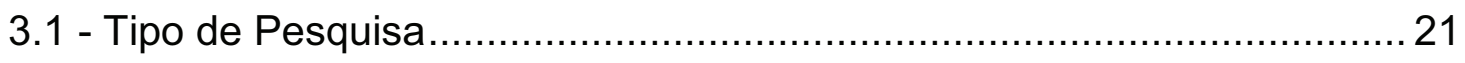

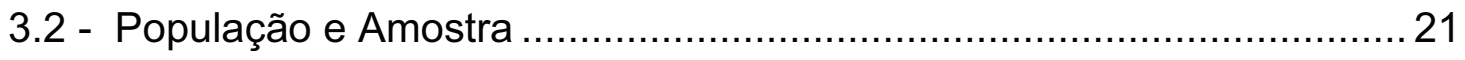

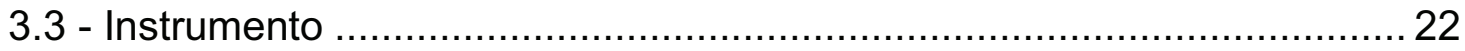

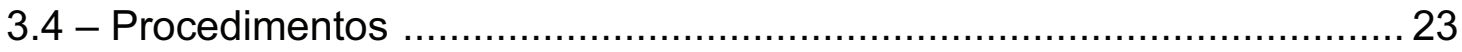

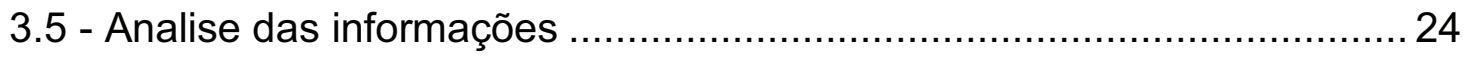

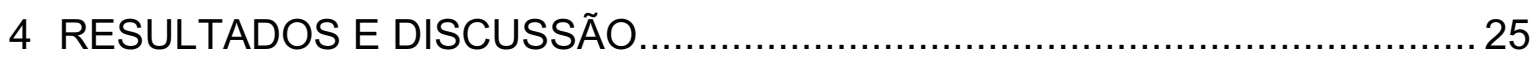

4.1 - Caracterização da Instituição e dos Participantes da Pesquisa ............. 25

4.1.1 - Caracterização da Instituição ………………....................... 25

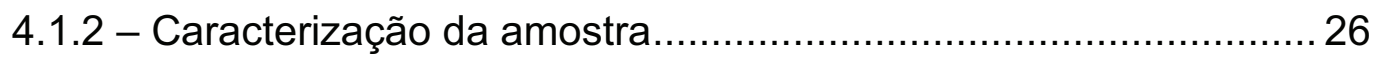

4.2 - Fatores de Comportamento de Civismo Organizacional ........................ 28

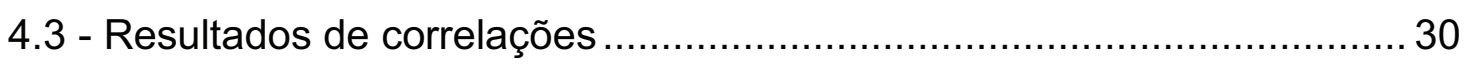

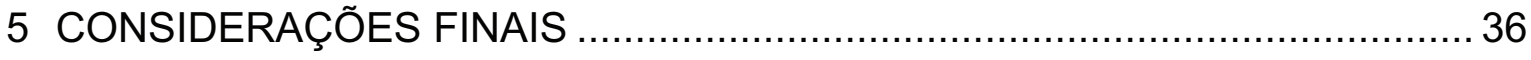

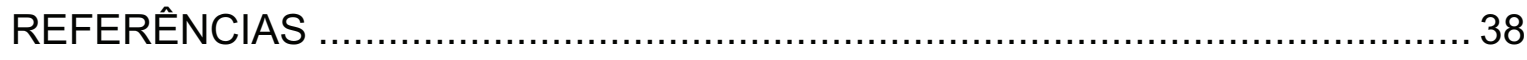

ANEXO A - Instrumento de coleta de dados .................................................. 40 


\section{INTRODUÇÃO}

O contexto atual em que as organizações se inserem se caracteriza pela participação ativa dos empregados e não pela obediência passiva, ou seja, o sujeito deve acreditar que ele e a empresa fazem parte do mesmo projeto, fortalecendo esta aliança.

Pesquisadores declaram que o comportamento de cidadania organizacional contribui para o alcance da efetividade organizacional. Porto e Tamayo (2003 p.394) assinalam que esse comportamento abrange as atitudes manifestadas voluntariamente pelos trabalhadores, os quais afluem para a obtenção das metas institucionais e corroboram para o crescimento da organização como um todo.

Katz e Kahn (1974, p. 381) "afirmam que organizações que se baseiam exclusivamente no papel prescrito possuem uma estrutura extremamente frágil”. O comportamento inovador e espontâneo é necessário para a organização, já que ele constitui um "desempenho acima dos requisitos de papel para a consecução das funções organizacionais".

Todos os conceitos apresentados acima norteiam atos espontâneos dos funcionários que refletem em benefícios às organizações.

No entanto, o termo cidadania organizacional compreende os comportamentos de dimensão tanto individual, a definição apresentada para estes comportamento enfatiza atividades espontâneas, inovadoras e pró-sociais, que beneficiam a organização, excedendo o papel formal e não são incitados por incentivos ou penalidade. De acordo com Porto e Tamayo (2003 p.394) "Siqueira (1995) retomando a definição original de Katz e Kahn (1974), sugere a expressão civismo nas organizações após fundamentar a inadequação do termo cidadania para expressar estes comportamentos".

Portanto, civismo nas organizações é definido como "atos espontâneos dos trabalhadores que beneficiam o sistema organizacional", segundo Porto e Tamayo (2005, p.37).

De acordo com Porto e Tamayo (2005), vários pesquisadores recorreram a psicologia social para compreender os comportamentos de civismo organizacional, e desenvolveram o estudos sobre os efeitos das variáveis atitudinais e de personalidade sobre o civismo nas organizações. 
Segundo Tamayo e Gondin (1996, p.63), os valores organizacionais são "princípios ou crenças, organizados hierarquicamente, relativos a metas e a comportamentos organizacionais desejáveis que orientam a vida da empresa e estão a serviço de interesses individuais, coletivos ou mistos".

De acordo com Freitas(1991, p.47) "a identificação de uma cultura está diretamente associada ao que o pesquisador considera como cultura, daí a existência de uma variedade de métodos, recomendações e passos, que abordam aspectos diferentes"

Todos os conceitos apresentados acima são de variáveis que refletem diretamente no desenvolvimento do comportamento de civismo nas organizações.

Partindo do pressuposto de que a contribuição de cada indivíduo para o processo de formulação de estratégias se dá através do desempenho de papéis organizacionais, assim o estudo do comportamento de civismo organizacional pode ressaltar a necessidade de as organizações valorizarem esse tipo de comportamento. Daí o propósito deste estudo, cujos objetivos são discutidos a seguir.

\subsection{Objetivos}

\subsubsection{Objetivo Geral}

O objetivo geral deste estudo é realizar uma análise comparativa dos comportamentos de civismo em um hospital universitário.

\subsubsection{Objetivos específicos}

O presente projeto pretende:

- Caracterizar os diferentes comportamentos de civismo presentes em um hospital universitário;

- Verificar relações entre comportamento de civismo e as variáveis gênero, faixa etária, tempo de trabalho, nível de escolaridade, tipo de vinculo e tipo de cargo;

- Sugerir ações que possam estimular o comportamento de civismo organizacional. 
Esta monografia está organizada da seguinte forma: apresenta-se introdução abordando o assunto, assim como as variáveis relacionadas ao comportamento de civismo organizacional.

$\mathrm{Na}$ fundamentação teórica, são discutidos os assuntos relacionados ao tema da pesquisa, no capítulo três é discutido a metodologia adotada para coleta e análise dos dados. Nos dois últimos capítulos são apresentados os resultados e discussões da pesquisa bem como as considerações finais. 


\section{FUNDAMENTAÇÃO TEÓRICA}

Segundo Porto e Tamayo (2003, p.393), "um crescente interesse pelo estudo do civismo nas organizações tem sido observado pela importância para sobrevivência e alcance da efetividade organizacional, que permitem formas particulares de manifestação e que não prevêem retribuição formal pelo sistema organizacional”.

Neste estudo serão abordadas diversas variáveis que se relacionam positivamente com o comportamento de civismo organizacional, tais como: Comportamento pró-social e extrapapel; comportamentos de espontaneidade e cidadania organizacional; comprometimento organizacional; valores organizacionais; cultura organizacional. Já Porto e Tamayo (2005, p.35) aponta "cultura organizacional como uma importante variável para o estudo dos comportamentos de civismo". Este teve como objetivo revisar os conceitos e pesquisas sobre civismo organizacional e fenômenos correlatos.

\subsection{Civismo organizacional e construtos similares}

O civismo organizacional retrata os atos espontâneos relacionados às necessidades emergentes da empresa, acompanhado um sistema que não é imposto, mas que cresce organicamente a partir das necessidades, crenças e ações das pessoas.

Carvalho e Gomes (2000 apud FERNANDES et. al., 2007) apontam a efetividade como o nível em que a organização alcança os seus objetivos, sem afetar os seus recursos e sem submeter os seus funcionários a um desempenho demasiado, podendo ser representada pela obtenção de objetivos ou o progresso no seu alcance. Assim, uma organização é efetiva desde que maximize os seus benefícios e aprimore a sua atuação dentro do seu setor, tendo em foco o aumento da qualidade.

Portanto, pode-se afirmar que a efetividade organizacional é um aspecto de grande importância dentro do contexto de civismo organizacional refletido em benefícios tanto para a organização como para trabalhador.

Os comportamentos inovadores e espontâneos, essenciais para a efetividade organizacional, evidenciados por Katz e Kahn (1974), foram foco de investigação de 
vários pesquisadores. Porém, a compreensão do construto foi diversificada e vários termos foram utilizados para a definição dos novos conceitos como: comportamentos pró-sociais; comportamentos de espontaneidade; comportamentos extrapapel e cidadania organizacional. Outros construtos que merecem atenção por suas proximidades com o conceito de civismo organizacional é o de comprometimento organizacional e cultura organizacional que também serão discutidos neste estudo.

Esta diversidade impõe um exame das convergências de cada termo detectado por Katz e Kahn (1974). Assim, buscar-se na presente revisão comparar aqueles conceitos em dois aspectos essenciais e suas dimensões, conforme definição elaborada por Katz e Kahn (1974).

O primeiro aspecto refere-se à espontaneidade dos atos, que ressalta o fato desses comportamentos não estarem previstos pelo papel funcional do trabalhador. O segundo aspecto refere-se à sua natureza benéfica para o sistema organizacional.

Estes fatores mencionados por Katz e Kahn (1974) são: atividades de cooperação com os demais membros da organização; ações protetoras ao sistema ou subsistema; sugestões criativas para melhoria organizacional; autotreinamento para maior responsabilidade organizacional; e criação de clima favorável à organização no ambiente externo.

No item a seguir serão abordadas as variáveis relevantes que ajudam a definir o comportamento de civismo organizacional.

\subsection{Comportamentos pró-sociais e extrapapel}

Segundo Porto e Tamayo (2003), comportamentos pró-sociais são aqueles que beneficiam e ajudam a outros indivíduos. No ambiente organizacional, podem ser definidos como comportamentos pró-sociais aqueles:

- Desempenhados por membros de uma organização;

- Dirigidos a outros indivíduos, grupos ou organização com quem a pessoa interage durante o desempenho de seu papel funcional e;

- Desempenhados com a intenção de promover o bem-estar do indivíduo, do grupo ou da organização a quem são dirigidos. 
Os comportamentos apontados podem estar definidos pelo papel funcional, compondo o desempenho do funcionário, como podem também se constituir em comportamentos extrapapel.

Os dois tipos de comportamento são considerados essenciais para o funcionamento organizacional. Considerando os aspectos apresentados, este conceito define comportamentos pró-sociais como comportamentos além do papel ocupacional e favorável à organização.

\begin{abstract}
Além disso, esses comportamentos englobam uma dimensão a mais ao considerar os comportamentos prescritos pelo papel. Outro elemento de distinção refere-se aos gestos de ajuda a outros indivíduos ou grupos, sem serem necessariamente benéficos à organização. Porém, quando este construto é operacionalizado, percebe- se que os comportamentos pró-sociais presentes nos instrumentos utilizado no estudo são benéficos ao sistema e englobam os fatores Cooperação, Sugestão Criativa e Criação de Clima Favorável à Organização no ambiente externo (PORTO ; TAMAYO, 2003, p.395).
\end{abstract}

O comportamento extrapapel compreende atividades próativas que colaboraram para o bem-estar organizacional. A definição apresentada é similar a de cidadania organizacional, de modo inclusivo, referindo-se à literatura sobre cidadania, para assimilação dos antecedentes de comportamentos extrapapel. Estes comportamentos, deste modo, adaptam-se à definição abordada por Katz e Kahn (1974).

\title{
2.3. Cidadania organizacional e comportamentos de espontaneidade
}

O termo "comportamentos de cidadania organizacional é uma expressão utilizada para representar ações informais dos trabalhadores que beneficiam a organização" (SIQUEIRA, 2003, p.165).

De acordo com Porto e Tamayo (2003, p. 394), "alguns autores entendem os comportamentos de cidadania organizacional como compreendendo uma dimensão tanta individual quanto grupal"

A partir do conceito de cidadania organizacional, ou seja, comportamentos que representam gestos cooperativos que não são prescritos pelo papel nem diretamente retribuídos pelo sistema de recompensa formal da organização, observa-se que os dois aspectos primordiais do conceito de Katz e Kahn são considerados (PORTO; TAMAYO, 2003, p.395). 
Pode-se dizer que os papéis descritos por Porto e Tamayo (2003) referem-se a comportamentos prescritos pelo papel, como: pontualidade e a não retirada de descansos desnecessários durante o horário de trabalho, levando os comportamentos de cidadania a se distanciarem dos comportamentos inovadores e espontâneos apontados como comportamentos de civismo devido à maneira como foi dirigido o estudo de Siqueira (1995).

A partir de estudos desenvolvidos, Siqueira (1995), Porto e Tamayo (2003, p.395) "apresenta não só uma definição clara do conceito, incluindo apenas comportamentos extrapapel e benéficos à organização, como também uma operacionalização pertinente, considerando os cinco fatores propostos por Katz e Kahn".

Com objetivo de fomentar os estudos já realizados, após fundamentar a inadequação do termo cidadania para designar estes comportamentos, Porto e Tamayo (2003) sugerem que esses comportamentos sejam designados como civismo nas organizações. Evidenciando que termo Cidadania Organizacional mesmo, tendo sido utilizado em pesquisas, os índices de confiabilidade obtidos são baixos, demonstrando a necessidade de aprimoramento, por esse motivo foi necessária a mudança do termo para Civismo Organizacional.

Katz e Kahn (1974, p.381). destaca que "entre os comportamentos espontâneos e os comportamentos de cidadania organizacional concluiu que os primeiros se diferenciam dos últimos por considerarem que pode haver uma recompensa formal à emissão desses comportamentos".

De acordo com Porto e Tamayo, (2003, p.396) "os comportamentos de espontaneidade organizacional são determinados por comportamentos extrapapel que são desempenhados voluntariamente e que contribuem para a efetividade organizacional".

Katz e Kahn (1974, p.381) retomam o conceito de comportamentos além da prescrição formal e debatem a sua relevância para a sobrevivência e a efetividade organizacional. Segundo estes autores, o comportamento inovador e espontâneo é um "desempenho acima dos requisitos de papel para a consecução das funções organizacionais" e englobaria:

1.atividades de cooperação com os demais membros da organização; as atividade da organização são intrinsecamente cooperativas e interrelacionadas; 2 . ações protetoras ao sistema ou subsistema; ações que visem 
salvar a vida da organização e o que a ela pertence; 3 . sugestões criativas ao sistema; criação de boas idéias para organização; 4. autotreinamento para maior responsabilidade organizacional; realizar atividades auto-educativas pelos membros para aprenderem a executar melhor seus próprios serviços e se prepararem para assumir posições mia responsáveis na organização, e;

5. criação de clima favorável para a organização no ambiente externo.

Este comportamento espontâneo, inovador e não presumido pelo papel funcional é fundamental, isso porque não seria possível prever todas as possibilidades das operações, assim como presumir as transformações do meio ou controlar a inconstância humana.

A definição apresentada para comportamentos de cidadania organizacional ressalta atividades espontâneas, inovadoras e pró-sociais, que favorecem a organização, que extrapola o papel formal e não são estimuladas por impulsos ou penalidades contratuais.

De acordo com Porto e Tamayo (2003) retomando a definição original de Katz e Kahn (1974), os comportamentos de civismo nas organizações são compreendidos como atos espontâneos dos trabalhadores que envolvem afeição ao sistema organizacional. Este conceito é qualificado por:

- Espontaneidade, característica básica que diferencia civismo nas organizações dos outros atos delimitados pelo cumprimento do dever contratual;

- Funcionalidade, garantia da natureza benéfica à organização;

- Irrestrição, permissão de formas particulares de manifestação;

- Isenção de retribuição prevista pelo sistema, comportamento de natureza social;

- Caráter público das ações, possibilidade de observação por parte do sistema organizacional (SIQUEIRA, 1995, p 85).

O conjunto desses atos do mesmo modo seriam similares aos já definidos por Katz e Kahn (1974). Neste estudo será empregado o termo civismo nas organizações de acordo com a definição apresentada por Porto e Tamayo (2003). Outros construtos semelhantes ao de civismo nas organizações que são encontrados na literatura serão abordados a seguir. 


\subsection{Comprometimento Organizacional}

Segundo Demo (2003), o domínio dos estudos reunidos sobre comprometimento no trabalho está distante de qualquer consenso quanto à própria definição do conceito e de como avaliá-lo. Porém, pode-se verificar a crescente concordância entre os estudiosos da área sobre a natureza multidimensional de comprometimento.

Mowday, Porter e Steers (1982 apud DEMO, 2003, p.189), "definem comprometimento organizacional como o vínculo do trabalhador com a organização que é construído por meio da internalização das normas, valores e regras da instituição".

Adicionalmente, Bastos (1993, p.58) define comprometimento organizacional como "uma adesão, um forte envolvimento do indivíduo com variados aspectos do ambiente de trabalho". Possuindo algumas características como: o desejo de permanecer e o orgulho por pertencer como membro da organização; a identificação com objetivos e valores organizacionais; e engajamento, exercer esforço em benefício da organização.

Existem outros tipos de abordagens sobre o comprometimento, que são relacionadas aos diferentes motivos pelos quais os indivíduos permanecem comprometidos, sendo denominadas de bases do comprometimento. Conforme Bastos (1993) são identificados cinco tipos distintos de bases do comprometimento, nos quesitos de conceituação e da forma de mensuração:

\footnotetext{
Atitudinal/Afetiva - relaciona-se com o processo de identificação do indivíduo com os objetivos e valores da organização; Instrumental/Calculativa abrange a avaliação das recompensas e custos, pelo empregado, relacionados com a sua condição integrante da organização; Normativa compreende o conjunto de normas sociais que determinam o vínculo entre indivíduo e organização; Sociológica - refere-se ao vínculo oriundo das relações de autoridade do empregador e a subordinação do empregado;Comportamental - envolve a consonância entre os atos ou comportamentos do indivíduo com suas cognições. O indivíduo comprometido possui sentimento de auto-responsabilidade pelos seus atos (BASTOS, 1993, P.59).
}

Posteriormente, foi proposto o enfoque multidimensional do comprometimento em três dimensões por Meyer e Allen (1991 apud MEDEIROS et al., 2003, p.194). Para os autores, o comprometimento organizacional é formado por três componentes: 
comprometimento como um apego a organização (affective commitment), ou afetivo; comprometimento percebido como custos associados a deixar a organização, [...] como instrumental; e comprometimento como uma obrigação de permanecer na organização, [...]normativo.

Segundo Meyer e Allen (1991 apud MEDEIROS, 2003, p.194), não existe uma única fonte de apego em relação ao trabalho e múltiplos apegos podem aumentar a força do vínculo entre indivíduo e organização.

Pode-se mencionar que vários autores estudaram o relacionamento entre 0 comprometimento e outras variáveis. Demo (2003) destaca que a organização que busca melhorar os seus padrões de qualidade e produtividade deve garantir, anteriormente, o compromisso dos seus membros organizacionais. Os resultados mostraram que os pesquisados apresentaram um nível maior de comprometimento comportamental, o que infere a existência de uma relação afetiva na identidade do empregado com a organização que faz parte.

De acordo com a pesquisa, pode-se afirmar que o comprometimento organizacional está diretamente ligado aos fatores de civismo organizacional, evidenciando que o comportamento de civismo corrobora para um bom relacionamento empregado $X$ organização.

\subsection{Cultura Organizacional}

De acordo com Freitas(1991, p.47) “a identificação de uma cultura está diretamente associada ao que o pesquisador considera como cultura, daí a existência de uma variedade de métodos, recomendações e passos, que abordam aspectos diferentes"

Pode-se dizer que cultura incidi em elementos compartilhados que compõe os padrões para perceber, pensar, agir e comunicar, representando então resistência às mudanças, frente aos valores, crenças, mitos e tabus, presentes no ambiente da empresa, que definem os comportamentos a serem seguidos. Essa variável pode direcionar as ações, induzindo à agilidade da equipe em relação à solução de seus problemas, principalmente quando é fortalecida por sua liderança.

Os elementos compartilhados são transmitidos pela organização a seus empregados na forma de objetivos e metas, normas, rituais e comunicação, dentre outros mecanismos. A estrutura básica da cultura de uma organização é formada por suas prioridades. 
A importância da cultura organizacional deve-se ao fato de constituir uma forte determinante da motivação na organização, que se deve às funções que o indivíduo desempenha. Pode-se dizer também que cultura organizacional é portanto, um conjunto de características únicas que permite diferenciar a organização. Corresponde ao que representa a personalidade no indivíduo e transmite a forma como os funcionários da organização se portam de acordo com o sistema de valores vigente.

Como já mencionado neste item, os valores organizacionais estão diretamente ligados ao comportamento de civismo, o item a seguir trata desta variável considerada muito importante para o estudo do comportamento.

\title{
2.6. Valores Organizacionais
}

Segundo Tamayo e Gondin (1996, p.63), os valores organizacionais são "princípios ou crenças, organizados hierarquicamente, relativos a metas e comportamentos organizacionais desejáveis que orientam a vida da empresa e estão a serviço de interesses individuais, coletivos ou mistos" .

Pode-se dizer que valores organizacionais estão diretamente ligados aos interesses tanto das organizações, como nos indivíduos nela inseridos, ou seja, para se caracterizar valores é necessário conhecer as necessidades de todos os envolvidos no processo.

As soluções dadas a essas necessidades dão origem ao valores ou às metas a serem alcançadas, tanto pelo empregado como pela empresa. Os valores são a representação dessas necessidades (TAMAYO; GONDIM; 1996)

De acordo com Tamayo, Mendes e Paz (2000, p.293),

\begin{abstract}
Todo empregado é capaz de identificar valores que predominam na sua organização e até detectar diferenças nos valores entre setores da empresa ou entre a sua empresa e outras que ele conhece. Uma organização pode ser descrita como sendo norteada por valores referentes aos aspectos técnico e administrativo, ao passo que uma outra pode ser percebida como colocando a ênfase no extremo oposto, centrando suas preocupações principalmente no bem-estar dos indivíduos que a compõem.
\end{abstract}

Os valores organizacionais expressam desejos tanto do indivíduo, como de um modo coletivo, representando metas que motivam suas ações. (TAMAYO; GONDIM, 1996) 
Segundo Tamayo e Gondim (1996, p.70) "os valores estão além das próprias normas e constituem uma espécie de ideologia. As normas definem explicitamente as formas de comportamento esperado dos membros de uma organização".

De acordo com o estudo, verifica-se que as variáveis apontadas estão todas relacionadas ao estudo do comportamento de civismo organizacional, uma vez que, todas elas evidenciam aspectos motivacionais relativos ao comportamento de espontaneidade. Não obstante, as similaridades entre os construtos discutidos neste capítulo, percebe-se a necessidade de explorar mais o conceito de civismo organizacional e sua relação com a efetividade das organizações.

Portanto, a seguir, descreve-se a metodologia adotada na pesquisa. 


\section{METODOLOGIA}

Segundo Vergara (2000, p.46) destaca que "o leitor deve ser informado sobre o tipo de pesquisa que será realizada, sua conceituação e justificativa à luz da investigação específica".

Portanto, neste item, será descrita a metodologia adotada para análise do comportamento de civismo em um hospital universitário.

\subsection{Tipo de pesquisa}

Vergara (2000) também destaca a importância de dois critérios básicos para classificação da pesquisa: quanto aos fins e quanto aos meios.

O método de investigação utilizado na presente pesquisa é o quantitativo a partir de survey que significa "levantamento de dados" de acordo Fink e Kosecoff (1985, p. 13 apud GÜNTHER, 1996, p. 387). Este método pode ser caracterizado como uma técnica para captação dados de pessoas a partir das suas idéias, sentimentos, planos, crenças, assim como origem social, educacional e financeira.

Quanto aos fins, a pesquisa será descritiva, pois fará exposição da população, estabelecimento de correlações entre variáveis, quanto ao comportamento de civismo. Quanto aos meios, trata-se de uma pesquisa bibliográfica e de campo. Bibliográfica por se tratar de um estudo desenvolvido com base em material publicado em livros, meios eletrônicos e periódicos científicos, e de campo porque a investigação ocorreu no local onde dispõe-se de elementos para explicar o comportamento de civismo e houve a aplicação de questionário, de acordo com Vergara (2000).

\subsection{População e amostra}

A presente pesquisa foi realizada em um hospital universitário que, na ocasião da coleta de dados, sua população total contava com 869 funcionários na assistência médica e 222 na assistência administrativa, entre os servidores do quadro permanente e prestadores de serviços.

A pesquisa foi realizada em dois setores do hospital, o Centro de Clínica Médica e o Centro de Pronto Atendimento, estes dois setores contavam com uma 
população total de 179 funcionários, e teve como exigência que os participantes tivessem pelo menos um ano de serviço na Instituição

O objetivo inicial era aplicar o instrumento de pesquisa para todos os colaboradores. No entanto, dada a exigüidade do tempo para coleta e análise dos dados, foram distribuídos pessoalmente 90 questionários e deste total foram resgatados 71 questionários. Desses três não foram aproveitados, considerando que a maior parte das questões estava em branco. Portanto, a amostra do estudo é composta por 68 funcionários de ambas as áreas de assistência médica e administrativa de dois setores distintos (Centro de Clínica Médica e Centro de Pronto Atendimento).

Pelo fato de ser uma Instituição de alta complexidade, que será caracterizada no capítulo de resultados, o critério utilizado para seleção da amostra foi por acessibilidade, que de acordo com Vergara (2000, p.51) "longe de qualquer procedimento estatístico, seleciona elementos pela facilidade de acesso a eles", considerando que as áreas de assistência médica e administrativa foram o foco da pesquisa.

\subsection{Instrumento}

Esta pesquisa utilizou um instrumento construído e validado por Porto e Tamayo (2003), denominado Escala de Civismo nas Organizações, composto por 41 itens respondidos em uma escala Likert de 5 pontos, onde 1 representa nunca e 5 sempre.

Estes itens se dividem em cinco fatores e representados da seguinte forma:

Fator 1 - Sugestões criativas ao sistema: reúne itens que expressam comportamentos dos empregados para aprimorar o funcionamento da organização.

Fator 2 - Proteção ao sistema: composto de itens sobre ações que visam zelar pelo patrimônio da Organização.

Fator 3 - Criação de clima favorável à Organização no ambiente externo: os itens deste fator dizem respeito a comportamentos de divulgação das vantagens e méritos da Organização fora do ambiente de trabalho.

Fator 4 - Autotreinamento: agrupa itens sobre comportamentos, dos funcionários, de busca de cursos e eventos que melhorem a sua performance no trabalho. 
Fator $\mathbf{5}$ - Cooperação com os colegas: inclui itens que refletem comportamentos de auxílio aos colegas de trabalho visando o benefício da Organização.

$\mathrm{Na}$ tabela a seguir, encontra-se a caracterização do referido instrumento.

Tabela - 1 Fatores, índices de confiabilidade e itens da ECO

\begin{tabular}{clccc}
\hline F & \multicolumn{1}{c}{ Nome } & $\alpha$ & Itens & $\begin{array}{c}\text { Quantidade } \\
\text { de itens }\end{array}$ \\
\hline F1 & Sugestões criativas ao sistema & 0,91 & $1,2,4,8,11,14,15,22,25,29,32,34,35$ & 13 \\
F2 & $\begin{array}{l}\text { Proteção ao sistema } \\
\text { F3 }\end{array} \quad \begin{array}{l}\text { Criação de clima favorável à organização } \\
\text { no ambiente externo }\end{array}$ & 0,80 & $6,7,16,17,19,24,41$ & 7 \\
F4 & Autotreinamento & $3,12,18,23,27,28,31,39$ & 8 \\
F5 & Cooperação com os colegas & 0,84 & $5,10,33,36$ & 4 \\
\hline
\end{tabular}

Fonte: Porto e Tamayo (2003, p.401)

O Instrumento foi desenvolvido a partir da escala de comportamento de cidadania organizacional, desenvolvida por Siqueira (1995), que tinha como objetivo medir os comportamentos por meio de auto-avaliação, que mesmo tendo uma boa fundamentação teórica e sendo utilizados em pesquisas, os índices de confiabilidade dos fatores eram baixos, tornando-se necessária a substituição do termo.

Ao final do questionário, foram incluídos os itens referentes aos dados demográficos e funcionais dos participantes (gênero, faixa etária, nível de escolaridade, tempo de trabalho, tipo de vínculo e tipo de cargo), conforme ANEXO A.

\subsection{Procedimentos}

O instrumento da pesquisa foi distribuído e recolhido pessoalmente pela pesquisadora. $\mathrm{O}$ instrumento foi aplicado no final do mês de fevereiro e início do mês de março de 2009, entregue para cada um dos participantes, por meio de material impresso no seu próprio local de trabalho.

Para participar da pesquisa, os colaboradores foram convidados a responder o questionário. Todos os voluntários foram orientados quanto ao preenchimento, na maior parte dos casos o questionário foi respondido no ato da entrega de acordo com 
a disponibilidade dos respondentes, em outras situações o questionário foi recolhido no dia posterior à distribuição.

No período de três semanas foram obtidos os questionários que representaram a amostra deste estudo.

Após o recolhimento do material, decorreu-se à preparação dos dados para análise.

\subsection{Análise das informações}

Para análise estatística dos dados utilizou-se o software Statistical Package for the Social Sciences (SPSS) versão 16.0 for Windows.

Foram calculados média e desvio padrão dos cinco fatores que expressam comportamento de civismo organizacional.

Além disso, foram calculadas Correlação de Pearson entre os referidos fatores e as seguintes variáveis demográficas: gênero, faixa etária, nível de escolaridade, tempo de trabalho, tipo de vínculo e tipo de cargo.

Para caracterizar a amostra foram utilizados gráficos e tabelas com freqüências e percentuais. 


\section{RESULTADOS E DISCUSSÃO}

\subsection{Caracterização da Instituição e dos Participantes da Pesquisa}

\subsubsection{Caracterização da Instituição}

Com relação a caracterização da instituição os dados que seguem foram coletados no site do Hospital onde ocorreu a pesquisa.

A Instituição teve seu funcionamento autorizado pelo Decreto n. ${ }^{0} 70.178$ de 21 de fevereiro de 1972. Foi inaugurado, oficialmente, em agosto de 1972, pelo então Presidente da República, General Emílio Garrastazu Médici, recebendo o nome de Hospital dos Servidores da União (HSU). (HUB, 2009)

$\mathrm{Na}$ época de sua inauguração, já contava com 240 leitos e várias especialidades .

Inicialmente conhecido como HSU, no início dos anos 80 , passou a ser o Hospital de Ensino da Universidade de Brasília e recebeu o nome de Hospital Docente-Assistencial (HDA). Em 1990, foi cedido à UnB em ato assinado pelo Presidente Fernando Collor e passou a se chamar Hospital Universitário de Brasília (HUB).

Desde então, com a cessão definitiva, as atividades de ensino, pesquisa e extensão passaram a representar o grande diferencial do Hospital em relação aos demais hospitais da cidade: o compromisso com a formação de novos profissionais da área de saúde (médicos, enfermeiros, dentistas, nutricionistas, farmacêuticos), indissoluvelmente ligado ao atendimento à população e à produção de conhecimento e desenvolvimento de novas tecnologias, adaptadas às características e exigências de nossa sociedade.

Além de receber os alunos de graduação dos diferentes cursos da universidade (Medicina, Enfermagem, Odontologia, Nutrição, Farmácia, Psicologia, Serviço Social, Administração, Educação, Arquitetura, etc.), o hospital universitário oferece estágios de pós-graduação e de nível médio em diferentes áreas.

A Residência Médica é uma das mais completas do Distrito Federal, incluindo 20 programas credenciados pelo MEC e 78 médicos residentes. (HUB 2009)

A pesquisa foi realizada com as equipes de assistência médica e administrativa de dois setores de alta complexidade do hospital. 


\subsubsection{Caracterização da Amostra}

Neste item serão apresentados os dados de caracterização da amostra que teve a participação de 68 respondentes.

Quanto ao gênero verificou-se que 24 respondentes $(35,3 \%)$ são do sexo masculino e $44(64,7 \%)$ da amostra são do sexo feminino. Em relação aos respondentes da área de assistência médica que corresponde a 50\% da amostra, $(32,35 \%)$ são do sexo masculino e $(67,65 \%)$ do sexo feminino, quanto à área de assistência administrativa a outra metade da amostra $(38,23 \%)$ dos participantes são do sexo masculino e $(67,77 \%)$ do sexo feminino. Assim a maior parte dos colaboradores da pesquisa são funcionários do sexo feminino.

Em relação à faixa etária, verifica-se que a idade dos participantes variava de 30 anos a 60 anos, sendo a média das idades igual a 45 anos, conforme demonstrado no Gráfico 1.

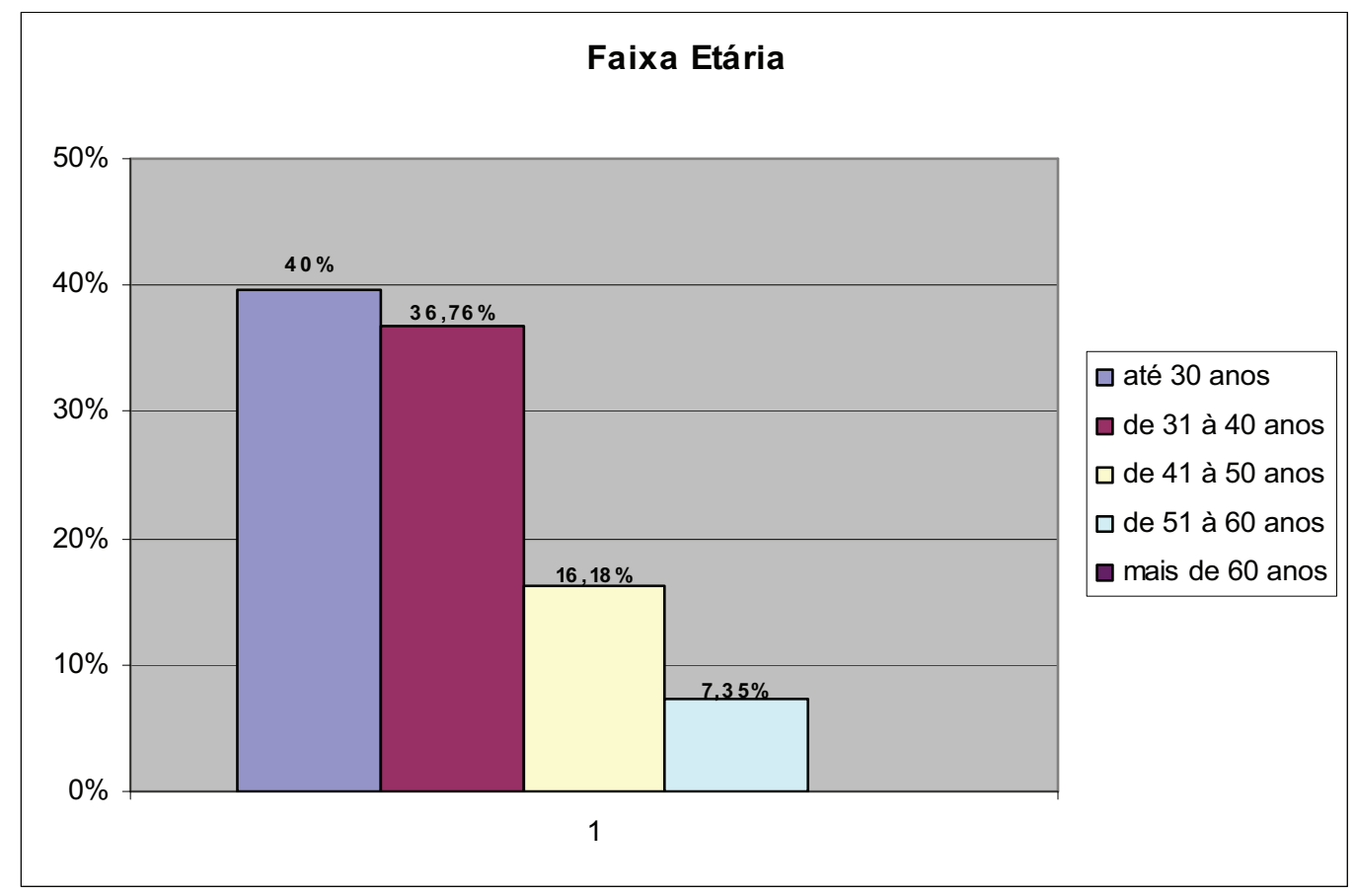

Gráfico 01: Faixa etária dos respondentes.

Como pode ser evidenciado os participantes da pesquisa são pessoas jovens.

A seguir, no Gráfico 2, são ilustrados resultados relacionados ao nível de escolaridade dos participantes. 
Tabela 2: Nível de escolaridade.

\begin{tabular}{lc}
\hline \multicolumn{1}{c}{ Nível de Escolaridade } & $\%$ \\
\hline Fundamental Incompleto & $1 \%$ \\
Fundamental Completo & $1 \%$ \\
Médio Incompleto & $3 \%$ \\
Médio Completo & $24 \%$ \\
Superior Incompleto & $18 \%$ \\
Superior Completo & $24 \%$ \\
Especialização & $22 \%$ \\
Mestrado & $3 \%$ \\
Doutorado & $4 \%$ \\
\hline
\end{tabular}

Quanto ao nível de escolaridade dos respondentes, o percentual de respondentes com os níveis fundamental incompleto e fundamental completo ambos foram baixos, o número de participantes com nível superior completo e especialização foram os maiores índices apresentados, evidenciando que a instituição conta com colaboradores com elevado nível de escolaridade.

Em relação ao tempo de serviço dos respondentes esse variava entre 1 a 35 anos, sendo o tempo médio de 7,69 anos, o que se pode verificar que se trata de funcionários com experiência, que possivelmente conhecem a organização.

No Gráfico 3, são demonstrados os dois tipos de vínculo dos participantes da pesquisa.

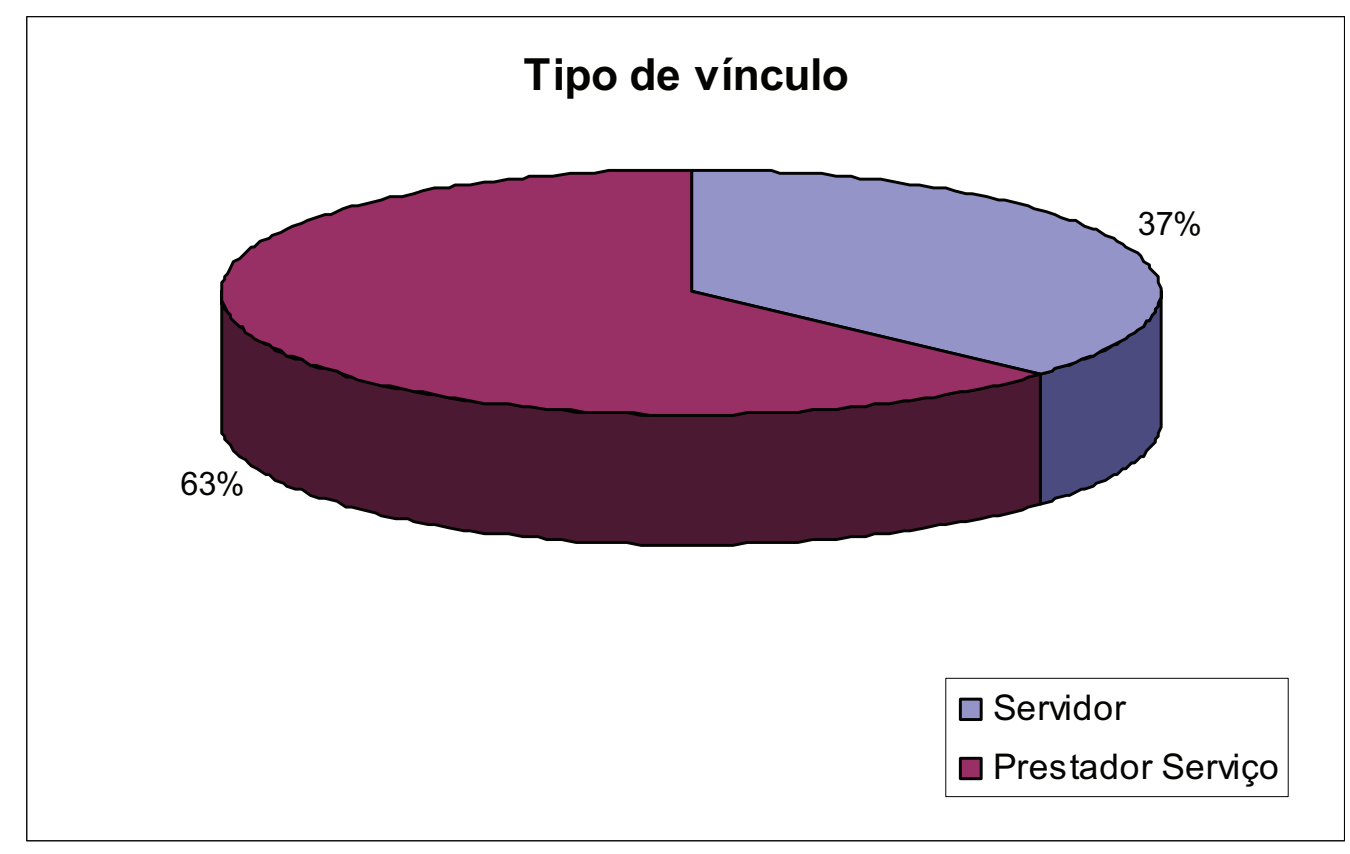

Gráfico 2: Tipo de vínculo. 
Neste item, observa-se que o maior número de participantes são os prestadores de serviços, ou seja, os funcionários extra-quadro que possuem um contrato temporário de trabalho com a Instituição.

Pode-se concluir com os resultados da amostra, que os participantes estavam aptos a responder o questionário aplicado, tendo em vista a exigência feita pela própria pesquisadora de que os respondentes possuíssem no mínimo um ano de serviço.

A seguir serão apresentados os resultados e a discussão os fatores que expressam comportamentos de civismo organizacional.

\title{
4.2. Fatores de comportamento de civismo organizacional
}

Para a análise dos comportamentos de civismo em um hospital universitário, o presente estudo utilizou o instrumento de pesquisa Escala de Civismo nas Organizações, validado por Porto e Tamayo (2003).

De acordo com Porto e Tamayo (2003 p. 393):

\begin{abstract}
Um crescente interesse pelo estudo do civismo nas organizações tem sido observado pela sua importância para sobrevivência e alcance da efetividade, civismo nas organizações são atos espontâneos dos trabalhadores que beneficiam o sistema organizacional, que permitem formas particulares de manifestação e que não prevêem retribuição formal pelo sistema organizacional.(PORTO; TAMAYO 2003, p.393)
\end{abstract}

Porto e Tamayo (2003) ainda estabeleceram que os comportamentos de civismo nas organizações são entendidos como atos espontâneos dos trabalhadores que envolvem dedicação ao sistema organizacional, este conceito é caracterizado por espontaneidade, funcionalidade, irrestrição, isenção de retribuição prevista pelo sistema, caráter público das ações.

Para descrever a percepção dos funcionários da organização pesquisada as respeito da escala de civismo organizacional encontram-se a seguir as médias, em ordem decrescente e os desvios padrões dos fatores da referida escala. 
Tabela 3- Médias e desvios padrões dos fatores de civismo organizacional

\begin{tabular}{|c|c|c|c|}
\hline & Fatores & Média & $\begin{array}{l}\text { Desvio } \\
\text { Padrão }\end{array}$ \\
\hline F2 & Proteção ao Sistema & 4,57 & 0,46 \\
\hline F5 & Cooperação com os colegas & 4,11 & 0,51 \\
\hline F3 & $\begin{array}{l}\text { Criação de Clima favorável à organização no } \\
\text { ambiente externo }\end{array}$ & 3,75 & 0,77 \\
\hline $\mathrm{F} 4$ & Autotreinamento & 3,61 & 0,91 \\
\hline $\mathrm{F} 1$ & Sugestões criativas ao sistema & 3,54 & 0,80 \\
\hline
\end{tabular}

A partir dos valores da Tabela 02 verificou-se a percepção dos respondentes da pesquisa em relação aos fatores da escala de civismo organizacional, em primeiro lugar aparece o Fator 2, "Proteção ao Sistema" apresentando média de 4,57 e desvio padrão 0,46, significando que a resposta dos participantes se situam entre freqüentemente e sempre, demonstram ações que visam zelar pelo patrimônio da organização

Em seguida, aparece o Fator 5, "Cooperação com os Colegas" com média 4,11 e desvio padrão de 0,51 , demonstrando que frequentemente os sujeitos apresentam comportamentos de auxilio aos colegas de trabalho visando o benefício da organização dos participantes.

Em terceiro lugar, aparece o Fator 3, "Criação de Clima Favorável à Organização no Ambiente Externo, com média de 3,75 e desvio padrão de 0,77 o que demonstra que a resposta dos respondentes se situaram entre as vezes e frequentemente, apresentam comportamentos de divulgação das vantagens e méritos da organização fora do ambiente de trabalho.

Em relação ao Fator 4, "Autotreinamento", que aparece em seguida com média de 3,61 e desvio padrão de 0,91, demonstrando que as respostas dos participantes se situaram entre as vezes e freqüentemente, ou seja, os comportamentos de busca de cursos e eventos que melhorem a sua performance no trabalho não são tão freqüentes.

E finalmente apresenta-se o Fator 1, "Sugestões Criativas ao Sistema" ,apresentando média de 3,54 e desvio padrão de 0,80, onde as respostas dos colaboradores situaram-se entre às vezes e frequentemente, evidenciando que os aspectos de sugestões de novas idéias à administração para beneficiar a organização 
pode-se dizer que não são tão freqüentes quanto aos demais praticados pelos participantes.

O maior desvio-padrão obtido foi relacionado ao Fator 4 'Autotreinamento', demonstrando maior variabilidade das respostas dos sujeitos em torno de média, isto é, há presença de diferentes percepções na amostra em relação ao Fator.

\subsection{Resultados de correlações}

Foi calculado o coeficiente de correlação de Pearson, entre as médias dos fatores e as variáveis demográficas. Apenas em relação ao Fator 4, foram observadas correlações significativas.

Serão apresentados a seguir os coeficientes significativos obtidos através da relação de Pearson entre os cinco fatores de comportamentos de civismo organizacional pesquisados e a caracterização dos participantes, conforme a Tabela 4.

Tabela 4 - Correlações significativas com os fatores e as variáveis independentes

\begin{tabular}{ccccc} 
Fatores & Faixa etária & $\begin{array}{c}\text { Nível de } \\
\text { Escolaridade }\end{array}$ & $\begin{array}{c}\text { Tempo de } \\
\text { Trabalho }\end{array}$ & $\begin{array}{c}\text { Tipo de } \\
\text { Cargo }\end{array}$ \\
F4 Autotreinamento & $r=-0,33\left(^{* *}\right)$ & $R=0,27\left(^{*}\right)$ & $r=-0,43\left(^{* *}\right)$ & $r=0,49\left(^{* *}\right)$ \\
& Sig. 0,006 & Sig. 0,027 & Sig. 0,0001 & Sig. 0,0001 \\
\hline
\end{tabular}

${ }^{*}$ Correlações significativas ao nível de 0,05.

${ }^{* *}$ Correlações significativas ao nível de 0,01.

Foram calculadas correlações entre os fatores e os itens de caracterização dos respondentes do questionário. Apenas o fator 4 'Autotreinamento' e as variáveis independentes faixa etária, nível de escolaridade, tempo de trabalho e tipo de cargo apresentaram correlações significativas. Na Tabela 3, verifica-se que a correlação foi significativa e negativa entre a variável faixa etária e o Fator 4 'Autotreinamento', indicando que quanto maior a idade dos respondentes os mesmos tendem a ter menor interesse em auto aperfeiçoamento profissional, ou seja não realizam atividades auto educativas para exercer melhor seus serviços e assumir posições responsáveis na organização, segundo Katz e Kahn (1974). Possivelmente esse fenômeno ocorre devido ao fato dos funcionários com mais idade tenham suas limitações para o avanço da tecnologia e o fato de seus concorrentes serem profissionais mais novos, e mais capacitados. 
Quanto maior o grau de escolaridade mais freqüentes os sujeitos recorrem ao autotreinamento, conforme pode ser observado na correlação feita entre a variável 'Nível de escolaridade' e o Fator 4.

Em relação a variável tempo de trabalho, verifica-se que quanto menor o tempo de trabalho menos freqüente os sujeitos buscam o Fator autotreinamento.

Para a variável tipo de cargo, foi necessário dicotomizá-la, em função do foco da pesquisa consistir em aplicar o instrumento para análise do comportamento de civismo para as áreas de assistência médica e administrativa.

A seguir, serão analisadas as médias e desvios padrão de cada item do instrumento, com objetivo de demonstrar melhor as respostas obtidas.

A Tabela 5, apresenta uma estatística descritiva dos itens que compõem o Fator 1'Sugestões Criativas ao Sistema'.

Tabela 5 - Estatística descritiva dos itens que compõem o fator sugestões criativas ao sistema

\begin{tabular}{|c|c|c|c|c|c|c|c|c|}
\hline & Sugestões criativas ao sistema & & mer & $\mathrm{eO}$ & ênc & & & \\
\hline Item & Afirmação & 1 & 2 & 3 & 4 & 5 & Média & DP \\
\hline 08 & $\begin{array}{l}\text { Pratico formas mais eficientes de realizar as } \\
\text { tarefas }\end{array}$ & 3 & 10 & 29 & 25 & 67 & 4,13 & 0,83 \\
\hline 29 & $\begin{array}{l}\text { Sugestões para melhorar o funcionamento } \\
\text { do setor }\end{array}$ & 0 & 6 & 20 & 15 & 17 & 3,78 & 0,93 \\
\hline 15 & $\begin{array}{l}\text { Soluções para as dificuldades de trabalho } \\
\text { que tenho }\end{array}$ & 2 & 4 & 18 & 26 & 16 & 3,76 & 0,99 \\
\hline 01 & $\begin{array}{l}\text { Sugestões para resolver problemas no setor } \\
\text { onde trabalho }\end{array}$ & 0 & 2 & 31 & 17 & 18 & 3,75 & 0,89 \\
\hline 14 & $\begin{array}{l}\text { Idéias novas sobre o meu trabalho na } \\
\text { organização }\end{array}$ & 0 & 4 & 24 & 26 & 12 & 3,70 & 0,84 \\
\hline 04 & $\begin{array}{l}\text { Novas rotinas que possam melhorar o } \\
\text { funcionamento do meu setor }\end{array}$ & 1 & 5 & 22 & 34 & 6 & 3,57 & 0,82 \\
\hline 35 & $\begin{array}{l}\text { Sugestões sobre a disposição do } \\
\text { ambiente físico da minha área }\end{array}$ & 4 & 10 & 15 & 22 & 16 & 3,54 & 1,18 \\
\hline 32 & Novas idéias para aumentar $\alpha$ produtividade & 3 & 7 & 19 & 30 & 8 & 3,49 & 0,99 \\
\hline 02 & $\begin{array}{l}\text { Novas idéias para o melhor aproveitamento } \\
\text { do ambiente físico }\end{array}$ & 3 & 11 & 20 & 23 & 11 & 3,41 & 1,08 \\
\hline 25 & $\begin{array}{l}\text { Sugestões à administração para melhorar a } \\
\text { estrutura organizacional }\end{array}$ & 2 & 13 & 20 & 22 & 10 & 3,37 & 1,06 \\
\hline 34 & $\begin{array}{l}\text { Sugestões para melhorar o gerenciamento } \\
\text { da organização }\end{array}$ & 4 & 10 & 22 & 19 & 11 & 3,35 & 1,12 \\
\hline 11 & Sugestão sobre novos produtos e serviços & 0 & 3 & 10 & 29 & 25 & 3,13 & 1,03 \\
\hline 22 & Novos usos para equipamentos ociosos & 6 & 17 & 15 & 18 & 7 & 3,05 & 1,18 \\
\hline & Média do fator Sugestões cr & vas & SIS & & & & 3,55 & 0,65 \\
\hline
\end{tabular}


O Fator 1 'Sugestões Criativas ao Sistema' é composto de treze itens, onde verifica-se que o item 08 se destaca pois é o que mais se aproxima de sempre (média: 4,13; dp: 0,83), indicando que de acordo com os respondentes sempre são adotadas formas mais eficientes de realização das tarefas. Outro que se destaca é o item 29, pois é o que mais se aproxima de frequentemente (média: 3,78; dp: 0,93), indicando que as sugestões para melhorar o funcionamento do setor são feitas frequentemente, em seguida aparece o item 15 muito próximo de frequentemente (média: 3,76; dp: 0,99), indicando que segundo os respondentes as 'soluções para as dificuldades de trabalho que tenho' acontecem freqüentemente, em relação aos fatores que apresentaram as menores médias destaca-se o item 11 (média: 3,13; dp: 1,03), indicando que os respondentes às vezes realizam sugestões sobre novos produtos e serviços, em seguida aparece o item 22 (média: 3,05; dp: 1,18), indicando que os participantes às vezes tomam iniciativa em relação novos usos para equipamentos ociosos,. Vale ressaltar que neste fator, todos os itens apresentaram média entre as vezes de frequentemente como pode ser observado na Tabela 4.

A seguir na Tabela 6, apresentam-se os itens que compõem o Fator 2 'Proteção ao sistema'.

\begin{tabular}{|c|c|c|c|c|c|c|c|c|}
\hline \multicolumn{2}{|r|}{ Proteção ao Sistema } & \multicolumn{5}{|c|}{ Número de Ocorrências } & \multirow[b]{2}{*}{ Média } & \multirow[b]{2}{*}{ DP } \\
\hline Item & Afirmação & 1 & 2 & 3 & 4 & 5 & & \\
\hline 17 & $\begin{array}{l}\text { Procuro conhecer os meus equipamentos de } \\
\text { trabalho }\end{array}$ & 0 & 0 & 3 & 15 & 50 & 4,69 & 0,55 \\
\hline 24 & $\begin{array}{l}\text { Uso com cuidado os equipamentos desta } \\
\text { organização }\end{array}$ & 0 & 0 & 2 & 20 & 46 & 4,65 & 0,54 \\
\hline 41 & Zelo pelo patrimônio desta organização & 0 & 0 & 2 & 22 & 44 & 4,62 & 0,55 \\
\hline 16 & Zelo da limpeza do ambiente de trabalho & 0 & 2 & 4 & 15 & 47 & 4,57 & 0,74 \\
\hline 19 & $\begin{array}{l}\text { Cuido com zelo dos equipamentos de } \\
\text { trabalho }\end{array}$ & 0 & 2 & 5 & 16 & 44 & 4,52 & 0,77 \\
\hline 06 & $\begin{array}{l}\text { Utilizo de forma adequada os equipamentos } \\
\text { da organização }\end{array}$ & 2 & 1 & 1 & 22 & 42 & 4,49 & 0,86 \\
\hline 07 & Evito desperdiçar material desta organização & 1 & 0 & 6 & 20 & 41 & 4,47 & 0,78 \\
\hline \multicolumn{7}{|c|}{ Média do fator Proteção ao Sistema } & 4,57 & 0,46 \\
\hline
\end{tabular}

Este fator é composto por sete itens, dentre eles se destacaram o item 17 (média: 4,69; dp: 0,55), indicando que os respondentes frequentemente cuidam com zelo dos equipamentos de trabalho, e em seguida o item 24 (média: 4,65; dp: 0,54), indicando 
que os participantes usam com cuidado os equipamentos da organização, já os itens que apresentam as menores médias aparece o item 07 (média: 4,47; dp: 0,78), quem mesmo tendo uma média menor indica que frequentemente os participantes evitam desperdiçar material da organização. É importante ressaltar que os itens deste fator apresentaram médias entre frequentemente e sempre, e que as respostas se concentraram entre as vezes e sempre.

A Tabela 7 a seguir apresenta os item que compõem o Fator 3, 'Criação de clima favorável à organização no ambiente externo'.

Tabela 7 - Estatística descritiva dos itens que compõem o fator Criação de um clima favorável à organização no ambiente externo

\begin{tabular}{|c|c|c|c|c|c|c|c|c|}
\hline \multicolumn{2}{|r|}{$\begin{array}{l}\text { Criação de clima favorável à organização } \\
\text { no ambiente externo }\end{array}$} & \multicolumn{5}{|c|}{ Número de Ocorrências } & \multirow[b]{2}{*}{ Média } & \multirow[b]{2}{*}{ DP } \\
\hline Item & Afirmação & 1 & 2 & 3 & 4 & 5 & & \\
\hline 3 & Procuro defender a empresa que trabalho & 0 & 5 & 12 & 23 & 26 & 4,06 & 0,94 \\
\hline 23 & $\begin{array}{l}\text { Costumo passar a melhor das impressões } \\
\text { para as pessoas que não conhecem esta } \\
\text { organização }\end{array}$ & 1 & 5 & 14 & 21 & 27 & 4,00 & 1,02 \\
\hline 39 & $\begin{array}{l}\text { Defendo os produtos ou serviços desta } \\
\text { organização }\end{array}$ & 1 & 3 & 19 & 28 & 17 & 3,84 & 0,91 \\
\hline 27 & \begin{tabular}{|l} 
Dou informações boas sobre esta \\
organização
\end{tabular} & 1 & 6 & 18 & 27 & 16 & 3,75 & 0,97 \\
\hline 28 & $\begin{array}{l}\text { Informo sobre o papel desta organização na } \\
\text { sociedade }\end{array}$ & 1 & 10 & 16 & 20 & 21 & 3,74 & 1,10 \\
\hline 18 & Descrevo as qualidades desta organização & 0 & 6 & 23 & 23 & 15 & 3,70 & 0,92 \\
\hline 31 & $\begin{array}{l}\text { Converso sobre as vantagens de trabalhar } \\
\text { nesta organização }\end{array}$ & 2 & 12 & 14 & 22 & 18 & 3,62 & 1,15 \\
\hline 12 & Costumo elogiar esta organização & 1 & 13 & 25 & 19 & 9 & 3,33 & 0,99 \\
\hline \multicolumn{7}{|c|}{ Média do fator Criação de um clima favorável à organização no ambiente externo } & 3,75 & 0,77 \\
\hline
\end{tabular}

Este fator é composto por oito itens, todos com média entre às vezes e sempre, destacando o item 03 (média: 4,06; dp: 0,54), indicando que a resposta dos participantes em relação a procurar defender a empresa que trabalham está entre frequentemente e sempre, em seguida o item 23, (média: 4,00; dp: 1,02), indicando que os respondentes frequentemente passam a melhor das impressões para as pessoas que não conhecem esta organização, em relação à menor média destaca-se o item 12 (média: 3,33; dp: 0,99), indicando que às vezes os respondentes elogiam a organização onde trabalham. Observa-se que os itens deste fator apresentam médias entre às vezes e frequentemente. 
A Tabela 8, reúne os itens do Fator 4 'Autotreinamento'.

Tabela 8 - Estatística descritiva dos itens que compõem o fator Autotreinamento

\begin{tabular}{c|l|c|c|c|c|c|c|c}
\hline \multicolumn{1}{c|}{ Autotreinamento } & \multicolumn{7}{c|}{ Número de Ocorrências } & \multicolumn{2}{c}{} \\
\hline Item & \multicolumn{1}{c|}{ Afirmação } & $\mathbf{1}$ & $\mathbf{2}$ & $\mathbf{3}$ & $\mathbf{4}$ & $\mathbf{5}$ & Média & DP \\
\hline 33 & $\begin{array}{l}\text { Busco cursos complementares que ampliem } \\
\text { a minha área de atuação }\end{array}$ & 4 & 6 & 14 & 28 & 16 & 3,68 & 1,11 \\
\hline 36 & $\begin{array}{l}\text { Busco participar de eventos da minha área } \\
\text { de atuação }\end{array}$ & 1 & 7 & 24 & 18 & 18 & 3,66 & 1,03 \\
\hline 5 & $\begin{array}{l}\text { Freqüento cursos de aperfeiçoamento } \\
\text { profissional }\end{array}$ & 3 & 6 & 20 & 20 & 18 & 3,66 & 1,11 \\
\hline 10 & $\begin{array}{l}\text { Procuro freqüentar cursos de reciclagem } \\
\text { profissional }\end{array}$ & 6 & 7 & 17 & 23 & 13 & 3,45 & 1,19 \\
\hline \multicolumn{7}{c}{ Média do fator Autotreinamento } \\
\hline
\end{tabular}

Composto de apenas quatro fatores, todos com média entre às vezes e frequentemente, destacando o item 33 (média: 3,68; dp: 1,11), indicando que a resposta dos participantes em relação a buscar cursos complementares que ampliem a área de atuação estão entre frequentemente e sempre, o item que apresentou menor média para este Fator foi o item 10 (média: 3,45; dp: 1,19), indicando que às vezes os respondentes procuram freqüentar cursos de reciclagem profissional.

$\mathrm{Na}$ Tabela 9 referente ao Fator 5 'Cooperação com os colegas', incluem-se itens que refletem comportamentos de auxílio aos colegas de trabalho visando o benefício da Organização. 
Tabela 9 - Estatística descritiva dos itens que compõem o fator Cooperação com os colegas

\begin{tabular}{|c|c|c|c|c|c|c|c|c|}
\hline \multicolumn{2}{|r|}{ Cooperação com os colegas } & \multicolumn{5}{|c|}{ Número de Ocorrências } & \multirow[b]{2}{*}{ Média } & \multirow[b]{2}{*}{ DP } \\
\hline Item & Afirmação & 1 & 2 & 3 & 4 & 5 & & \\
\hline 20 & $\begin{array}{l}\text { Ofereço-me para ajudar um colega que está } \\
\text { com dificuldade no trabalho }\end{array}$ & 0 & 2 & 6 & 16 & 44 & 4,50 & 0,78 \\
\hline 21 & $\begin{array}{l}\text { Repasso meus conhecimentos para colegas } \\
\text { de trabalho }\end{array}$ & 0 & 2 & 4 & 24 & 36 & 4,42 & 0,75 \\
\hline 13 & $\begin{array}{l}\text { Oriento um colega menos experiente no } \\
\text { trabalho }\end{array}$ & 0 & 3 & 8 & 19 & 38 & 4,35 & 0,86 \\
\hline 38 & $\begin{array}{l}\text { Colaboro quando colegas me pedem auxilio } \\
\text { no trabalho }\end{array}$ & 0 & 1 & 10 & 22 & 35 & 4,34 & 0,78 \\
\hline 40 & Ajudo colegas na resolução de problemas & 0 & 1 & 16 & 22 & 29 & 4,16 & 0,84 \\
\hline 30 & $\begin{array}{l}\text { Complemento o trabalho de colegas, quando } \\
\text { solicitado }\end{array}$ & 0 & 3 & 15 & 23 & 27 & 4,09 & 0,89 \\
\hline 26 & $\begin{array}{l}\text { Ofereço ajuda aos meus colegas que } \\
\text { estejam sobrecarregados }\end{array}$ & 0 & 2 & 13 & 32 & 21 & 4,06 & 0,79 \\
\hline 37 & $\begin{array}{l}\text { Ofereço apoio emocional a colegas com } \\
\text { problemas pessoais }\end{array}$ & 2 & 6 & 17 & 21 & 21 & 3,79 & 1,08 \\
\hline 9 & $\begin{array}{l}\text { Ofereço-me para substituir um colega que } \\
\text { faltou ao trabalho }\end{array}$ & 2 & 10 & 30 & 14 & 11 & 3,33 & 1,02 \\
\hline \multicolumn{7}{|c|}{ Média do fator Cooperação com os colegas } & 4,12 & 0,51 \\
\hline
\end{tabular}

Composto por nove itens este fator teve como destaque o item 20, (média: 4,50; dp: 0,78), indicando que os participantes se oferecem para ajudar um colega que está com dificuldades no trabalho frequentemente, em relação ao item com menor média destaca-se o item 9, (média: 3,33 ; dp: 1,02), indicando que às vezes os respondentes se oferecem para substituir um colega que faltou ao trabalho. Os itens deste fator apresentaram as médias entre às vezes e sempre. 


\section{CONSIDERAÇÕES FINAIS}

O presente estudo objetivou realizar uma análise em um hospital universitário dos comportamentos de civismo organizacional. Pode-se verificar, a partir da análise dos dados segundo os participantes da pesquisa, que o comportamento de civismo organizacional considerado como atos espontâneos dos trabalhadores, estão presentes na organização.

Pode-se concluir que os comportamentos de civismo mais freqüentes na amostra foram Fator 2 'Proteção ao sistema', evidenciando que os respondentes freqüentemente e sempre, apresentam ações que visam salvar a vida organizacional e o que a ela pertence, em seguida aparece o Fator 5 'Cooperação com os colegas', indicando que os respondentes freqüentemente cooperam com os demais membros, logo após aparece o Fator 3, 'Criação de clima favorável a organização no ambiente externo', indicando que a freqüência das respostas dos participantes da pesquisa está entre às vezes e sempre para este fator que procura criar um clima favorável à organização, em seguida aparece o Fator 4 'Autotreinamento', o que demonstra que às vezes os participantes buscam aperfeiçoamento profissional, e finalmente temos o Fator 1 'Sugestões criativas ao sistema', indicando que às vezes e freqüentemente os respondentes participam da criação de boas idéias para a organização. A partir do estudo realizado observa-se que os itens que apresentaram as menores médias indicam que a organização necessita atentar para a melhoria do clima organizacional tendo em vista os resultados obtidos em relação ao Fator que reflete comportamentos de auxílio aos colegas de trabalho, visando o benefício da organização.

Este estudo pretendeu trazer contribuições para melhor orientar as ações da Instituição, no sentido de aprimorar seu desempenho futuro. Não foi possível realizar um estudo mais amplo devido ao curto tempo destinado. No entanto, essas limitações podem ser vistas como uma oportunidade para estudos futuros. Destaca-se também, como limitação, a pouca literatura nacional sobre o assunto.

Espera-se que a pesquisa apresentada contribua para o desenvolvimento de ações futuras dos comportamentos de civismo organizacional, assim como os outros aspectos a ele relacionados, como comprometimento organizacional e valores organizacionais, dentro da organização.

Por tratar-se de um tema pouco abordado, porém muito importante, sugere-se a realização de futuros estudos referentes ao comportamento de civismo 
organizacional em outras áreas da instituição, para identificação de problemas a serem solucionados, bem como a abordagem das variáveis relacionadas, ressaltando a questão do clima organizacional que o estudo evidenciou uma certa deficiência em relação a esta variável, que assim como as demais são de grande importância para o crescimento organizacional e do indivíduo nela inserido. 


\section{REFERÊNCIAS}

BASTOS, A. V. B. Comprometimento Organizacional: um balanço dos resultados e desafio que cercam essa tradição de pesquisa. Revista de Administração Contemporânea, São Paulo, v.33, p. 52-64, mai./jun. 1993.

DEMO, G.. Comprometimento no trabalho: uma síntese do estado da arte e uma revisão da produção nacional. Revista de Psicologia Organizações e Trabalho, v.3 n.2, jul./dez., 2003.

FERNANDES, M. N.; BARELE, R.F; SANTOS, T. R. C.; COSTA, T. P. A.; JUNIOR, S. G.. Percepção de efetividade organizacional: construção e validação de uma medida do construto. Revista Psicologia: Organizações e Trabalho, v. 7, n.2, jul./dez., p. 89-102, 2007.

FREITAS, M. E. Cultura organizacional: formação, tipologia e impactos. São Paulo: Makron Books,1991.

GÜNTHER, H. Desenvolvimento de instrumento para levantamento de dados (survey). In: PASQUALI, L. Teoria e métodos de medida em ciências do comportamento. UnB-INEP, cap. 15, p. 387-403, Brasília, 1996.

KATZ, D.; KAHN, R. L.. Psicologia social das organizações. São Paulo: Atlas, 1974.

MEDEIROS, C. A. F; ENDERS, W. T. Validação do modelo de conceitualização de três componentes do comprometimento organizacional (Meyer e Allen, 1991). Revista de Administração Contemporânea, v.2 n.3, p. 67-87, set./dez., 1998.

PORTO, J.B.; TAMAYO, A. Desenvolvimento e validação da escala de civismo nas organizações. Estudos de Psicologia, Natal, v.8, n.3, p. 393-402, 2003.

PORTO, J. B; TAMAYO, A. Valores organizacionais e civismo nas organizações. Revista de Administração Contemporânea, v.9, n.1 p.35-52, jan./mar., 2005.

SIQUEIRA, M. M. M. Antecedentes de comportamentos de cidadania organizacional: a análise de um modelo pós-cognitivo. Tese (Doutorado em Psicologia), Universidade de Brasília, Brasília, 1995. 
SIQUEIRA, M. M. M. Construção Preposição e análise de um modelo para comportamento de cidadania organizacional. Revista de Administração Contemporânea, Edição Especial, p.165-184, 2003.

TAMAYO, A.; GONDIM, M. G. C. Escala de valores organizacionais.Revista de Administração da USP - RAUSP. São Paulo, v.31, n.2, p. 62-72, 1996.

TAMAYO, A. ; MENDES, A. M. ; PAZ, M. T.. Inventário de valores organizacionais. Estudos de Psicologia Natal, v. 5, n. 2, p. 289-315, 2000.

VERGARA, S. C. Projetos e relatórios de pesquisa em administração. 9.ed. São Paulo: Atlas, 2007. 
ANEXOS 


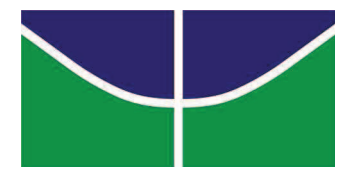

Universidade de Brasília (UnB)

Faculdade de Economia, Administração, Contabilidade e Ciência da Informação e Documentação (FACE)

\section{Prezado colaborador,}

Esta pesquisa faz parte da monografia do curso de Especialização em Gestão Universitária, apresentada ao Programa de Pós-Graduação em Administração da Faculdade de Administração, Contabilidade, Economia e Ciência da Informação e Documentação (FACE), que tem como tema o estudo do civismo organizacional.

O presente questionário tem como objetivo avaliar "o civismo organizacional considerado como atos espontâneos dos colaboradores que beneficiam o sistema organizacional", com base na definição proposta por Porto e Tamayo (2003, p. 393).

Não é necessário se identificar. Não existem respostas certas ou erradas e as informações prestadas não serão utilizadas para outro fim, que não o da pesquisa.

Desde já, agradeço a sua colaboração e coloco-me à disposição para quaisquer esclarecimentos.

Atenciosamente,

\section{Rejane Maria Moreira dos Santos}

e-mail: rejanemms@gmail.com 
- Em relação às suas atividades diárias no trabalho, avalie com base na escala abaixo, o quanto você apresenta os comportamentos listados nos itens a seguir de 1 a 5 , sendo 1 o grau mínimo e 5 o grau máximo.

- Assinale com um X apenas UMA opção de reposta para cada item.

\section{Escala a ser utilizada}

1

\section{$\Gamma$}

2

T

3

T

4

Às vezes

Freqüentemente

5

Sempre

\begin{tabular}{|c|c|c|c|c|c|c|}
\hline & & 1 & 2 & 3 & 4 & 5 \\
\hline 1. & Sugestões para resolver problemas no setor onde trabalho. & & & & & \\
\hline 2. & Novas idéias para o melhor aproveitamento do ambiente físico. & & & & & \\
\hline 3. & Procuro defender a empresa que trabalho. & & & & & \\
\hline 4. & Novas rotinas que possam melhorar o funcionamento do meu setor. & & & & & \\
\hline 5. & Freqüento cursos de aperfeiçoamento profissional. & & & & & \\
\hline 6. & Utilizo de forma adequada os equipamentos da organização & & & & & \\
\hline 7. & Evito desperdiçar material desta organização. & & & & & \\
\hline 8. & Realizo formas mais eficientes de realizar as tarefas. & & & & & \\
\hline 9. & Ofereço-me para substituir um colega que faltou ao trabalho. & & & & & \\
\hline 10. & Procuro freqüentar cursos de reciclagem profissional. & & & & & \\
\hline 11. & Sugestões sobre novos produtos e serviços. & & & & & \\
\hline 12. & Costumo elogiar esta organização. & & & & & \\
\hline 13. & Oriento um colega menos experiente no trabalho. & & & & & \\
\hline 14. & Idéias novas sobre o meu trabalho nesta organização. & & & & & \\
\hline 15. & Soluções para as dificuldades de trabalho que tenho. & & & & & \\
\hline 16. & Zelo da limpeza do ambiente de trabalho & & & & & \\
\hline 17. & Procuro conhecer os meus equipamentos de trabalho. & & & & & \\
\hline 18. & Descrevo as qualidades desta organização. & & & & & \\
\hline 19. & Cuido com zelo dos equipamentos de trabalho. & & & & & \\
\hline 20. & Ofereço-me para ajudar um colega que está com dificuldade no trabalho. & & & & & \\
\hline 21. & Repasso meus conhecimentos para colegas de trabalho. & & & & & \\
\hline 22. & Novos usos para equipamentos ociosos. & & & & & \\
\hline 23. & $\begin{array}{l}\text { Costumo passar a melhor das impressões para as pessoas que não conhecem esta } \\
\text { organização. }\end{array}$ & & & & & \\
\hline 24. & Uso com cuidado os equipamentos desta organização. & & & & & \\
\hline 25. & Sugestão à administração para melhorar a estrutura da organização. & & & & & \\
\hline 26. & Ofereço ajuda aos colegas que estejam sobrecarregados. & & & & & \\
\hline 27. & Dou informações boas sobre esta organização. & & & & & \\
\hline 28. & Informo sobre o papel desta organização na sociedade. & & & & & \\
\hline 29. & Sugestão para melhorar o funcionamento do setor. & & & & & \\
\hline 30. & Complemento o trabalho de colegas, quando solicitado. & & & & & \\
\hline 31. & Converso sobre as vantagens de trabalhar nesta organização. & & & & & \\
\hline
\end{tabular}


Escala a ser utilizada

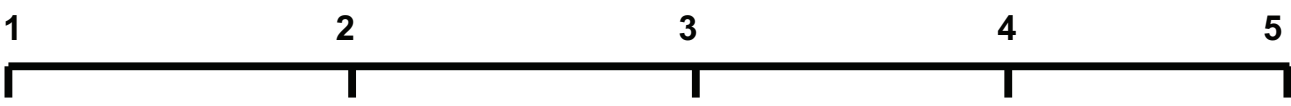

Nunca Raramente Às vezes Freqüentemente Sempre

\begin{tabular}{|c|c|c|c|c|c|c|}
\hline & & 1 & 2 & 3 & 4 & 5 \\
\hline 32. & Novas idéias para aumentar a produtividade. & & & & & \\
\hline 33. & Busco cursos complementares que ampliem minha área de atuação. & & & & & \\
\hline 34. & Sugestões para melhorar o gerenciamento da organização. & & & & & \\
\hline 35. & Sugestões sobre a disposição do ambiente físico da minha área. & & & & & \\
\hline 36. & Busco participar de eventos da minha área de atuação. & & & & & \\
\hline 37. & Ofereço apoio emocional a colegas com problemas pessoais. & & & & & \\
\hline 38. & Colaboro quando colegas me pedem auxilio no trabalho. & & & & & \\
\hline 39. & Defendo os produtos ou serviços desta organização. & & & & & \\
\hline 40. & Ajudo colegas na resolução de problemas. & & & & & \\
\hline 41. & Zelo pelo patrimônio desta organização. & & & & & \\
\hline
\end{tabular}

Para Finalizar, pedimos por gentileza responder alguns itens a fim de caracterizar os participantes da pesquisa.
A - Gênero
7. ( ) Especialização
1. ( ) Feminino
8. ( ) Mestrado
2. ( ) Masculino
9. ( ) Doutorado

\section{B - Faixa Etária}

1. ( ) até 30 anos

2. ( ) de 31 à 40 anos

3. ( ) de 41 à 50 anos

4. ( ) de 51 à 60 anos

5. ( ) mais de 60 anos

\section{C - Nível de escolaridade}

1. ( ) Fundamental Incompleto

2. ( ) Fundamental Completo

3. ( ) Médio Incompleto

4. ( ) Médio Completo

5. ( ) Superior Incompleto

6. ( ) Superior Completo
D - Tempo de trabalho na instituição anos.

\section{E - Tipo de Vinculo com a instituição \\ 1. ( ) Servidor \\ 2. ( ) Prestador de Serviços HUB}

\section{F - Tipo de Cargo}

1. ( ) Administração

2. ( ) Assistência médica

3. ( ) Assistência em enfermagem

4. ( ) Execução de serviços gerais

5. ( ) Auxiliar Operacional

6. ( ) Outros 